Article

\title{
Facile One-Step Method to Fabricate a Slippery Lubricant-Infused Surface (LIS) with Self-Replenishment Properties for Anti-Icing Applications
}

\author{
Juantao Zhang ${ }^{1}$, Bei Liu ${ }^{2}$, Yan Tian ${ }^{3}$, Fushan Wang ${ }^{4}$, Qingguo Chen ${ }^{4}$, Fan Zhang ${ }^{2}$, \\ Hongchang Qian ${ }^{2, *}$ and Lingwei $\mathrm{Ma}^{2}$ \\ 1 CNPC Tubular Goods Research Institute, State Key Laboratory for Performance and Structure Safety of \\ Petroleum Tubular Goods and Equipment Materials, Xi'an, Shaanxi 710077, China; \\ zhangjuantao@cnpc.com.cn \\ 2 Corrosion and Protection Center, Institute for Advanced Materials and Technology, \\ University of Science and Technology Beijing, Beijing 100083, China; s20171361@xs.ustb.edu.cn (B.L.); \\ B20160529@xs.ustb.edu.cn (F.Z.); mlw1215@ustb.edu.cn (L.M.) \\ 3 Hengyang Valin Steel Tube Co., Ltd., Hengyang, Hunan 421001, China; tianyan@hysteeltube.com \\ 4 Petro China Traim Oilfield Company, Korla 841000, China; wangfus@petrochina.com.cn (F.W.); \\ chenqg-tlm@petrochina.com.cn (Q.C.) \\ * Correspondence: qianhc@ustb.edu.cn; Tel.: +86-010-6233-4300
}

Received: 29 December 2019; Accepted: 22 January 2020; Published: 31 January 2020

\begin{abstract}
In this work, a slippery lubricant-infused surface (LIS) was prepared by simple one-step mixing of polydimethylsiloxane (PDMS) resin and dimethyl silicone oil (PMX-200) directly. Silicone oil showed good compatibility with PDMS resin, and the added amount of silicone oil had no significant effect on the surface morphology of LIS. According to the results of surface observations, once the silicone oil film anchored on the LIS was removed, the silicone oil inside the PDMS polymer automatically diffused to the surface and formed a new silicone oil film again in a short time. Furthermore, with the increase of silicone oil content, the oil self-replenishment speed and amount of the LIS were enhanced, which also promoted a decrease of the surface water sliding angle and the improvement of the lubrication ability of the LIS. In the icing/deicing cycle tests, the slippery LIS still maintained very low ice adhesion strength after 24 cycles, showing excellent anti-icing performance.
\end{abstract}

Keywords: lubricant-infused surface; anti-icing; self-replenishment

\section{Introduction}

The accumulation of solid ice on the surfaces of metal materials and metal equipment in cold environments not only aggravate energy consumption, but also pose a threat to people's safety during the shedding process. The problem of icing seriously interferes with the electricity transportation, wind power generation, aerospace, and other important fields [1-3]. To solve this problem, a variety of deicing methods have been proposed, such as thermal melting and mechanical deicing [4-6]. Nevertheless, these methods are difficult to operate or are costly. Hence, in recent years, more researchers have begun to focus on how to prevent ice formation and to reduce ice adhesion. The development of anti-icing coating or surfaces provides a good idea for this research direction.

The traditional anti-icing surfaces are mainly liquid-repellent surfaces represented by superhydrophobic surfaces [7-9]. Superhydrophobic surfaces generally refer to the material surfaces with a water contact angle greater than $150^{\circ}$ and a rolling angle less than $10^{\circ}$ [10]. Its appearance is inspired by natural lotus leaves [11]. The preparation of a superhydrophobic surface 
needs to consider the suitable surface microstructure and low surface energy material [12,13]. Actually, the superhydrophobic surface has shown great application potential and prospects in many fields, such as anti-fouling, drag reduction, self-cleaning, anti-corrosion, and anti-icing [14-18]. Superhydrophobic surfaces can reduce the stable contact between water droplets and material surfaces and promote the free shedding of water droplets before freezing. In addition, the superhydrophobic surface can increase the energy required for ice nucleation and delay the freezing time [19], which allows it to be considered for anti-icing applications. However, the poor durability of superhydrophobic surfaces is an important problem that restricts its application. In severe application environments, the air film on superhydrophobic surfaces is easily lost [20-22]. Once the air film is broken through, water and the surface will come into complete contact, and the rough microstructure on the superhydrophobic surface will increase the ice adhesion strength. Hence, new anti-icing surfaces need to be developed.

Inspired by the natural pitcher plant, researchers began to use oil films instead of unstable air films to further develop slippery liquid-infused surfaces (LISs) for anti-icing application [23-25]. Compared with the air film, the oil film on the LIS can maintain non-wettability and insolubility in most aqueous solutions for a long time, which can effectively block the direct contact between water and the material surface [26,27]. Meanwhile, the lubrication of the oil film results in a low contact angle hysteresis, which makes the water droplet easily slide away from the oil film surface in the hydrophobic state [28]. In addition, in the face of physical damage, the LIS can maintain integrity depending on the fluidity of the oil film and complete the self-healing of the surface morphology without external stimulation $[29,30]$. These properties make the LIS ideal for use in the field of anti-fouling, anti-bacterial, anti-corrosion, anti-icing, etc. [31-34]. Carmalt et al. prepared a slippery LIS by infusing Krytox lubricating oil into a titanium dioxide $\left(\mathrm{TiO}_{2}\right) /$ tin dioxide $\left(\mathrm{SnO}_{2}\right)$ composite thin film [35]. This surface effectively slowed ice formation for $>30 \mathrm{~min}$ at $-10^{\circ} \mathrm{C}$. Zhang et al. used fluorinated tubular $\mathrm{SiO}_{2}$ as the porous structure and constructed a slippery LIS on aluminum alloy after modification by Krytox 100 lubricating oil [36]. The surface exhibited a low ice adhesion strength in the icing/deicing cycle tests. It can be seen that the slippery LIS has shown great potential in the anti-icing application, and silicone oil was also widely chosen as the lubricant for anti-icing LIS due to its non-wettability. However, in the existing studies, most slippery LISs adopted complex preparation methods, such as the sol-gel method and chemical etching method $[37,38]$, which also enhanced the cost of preparation. Moreover, once the oil film was lost due to evaporation and other reasons, very few LISs had the ability to repair the oil film, which was also detrimental to the durability of anti-icing application [39].

In this work, we introduce a facile and effective one-step mixing method to prepare a self-replenishing polydimethylsiloxane (PDMS) resin/dimethyl silicone oil LIS and study its anti-icing performance for the first time. PDMS is a kind of widely used, chemically inert, non-flammable, nontoxic, and biocompatible silicon-based polymer. Due to its good lubricating performance and excellent adaptability to lubricants, PDMS is often considered as a suitable material to prepare LISs $[40,41]$. Considering that the PDMS based materials can not only be used as coatings, but also ca be used alone, we only studied the properties of the polymer itself in this work. By adjusting the proportion of silicone oil, the lubricity, self-replenishing ability, and anti-icing properties of the LIS can be tuned. An optical microscope was used to observe the self-replenishing process of silicone oil on the surface, and the oil supplement amount was measured by the weight loss method. Subsequently, the wettability and lubricity of the LIS before and after self-supplementation were characterized by contact angle and sliding angle measurements. Finally, the icing/deicing cycle tests were conducted to study the anti-icing property of the LIS. 


\section{Materials and Methods}

\subsection{Materials}

The PDMS prepolymer with curing agent (Sylgard 184) and dimethyl silicone oil (PMX-200) were purchased from Dow Corning. All solvents and reagents were obtained from Sinopharm and used as received without further purification.

\subsection{Preparation of LIS}

To prepare the LIS, the PDMS prepolymer and its curing agent were first added to a beaker at a ratio of 10:1 w/w. Subsequently, dimethyl silicone oil (viscosity $100 \mathrm{cp}$ ) was mixed into the beaker with different mass ratios $\left(W_{\text {PDMS resin }}: W_{\text {Silicone oil }}=1: 0,1: 1,1: 2\right)$. After magnetic stirring at room temperature (RT) for $20 \mathrm{~min}$, the three mixtures were put into a vacuum drying oven and vacuumed at RT for $1 \mathrm{~h}$ to remove bubbles. Finally, the three mixtures were heated and solidified at $80{ }^{\circ} \mathrm{C}$ for $4 \mathrm{~h}$ to obtain the required samples. The samples obtained from different mixtures were hereinafter referred to as pure sample $\left(W_{\text {PDMS resin }}: W_{\text {Silicone oil }}=1: 0\right), 1 \mathrm{P} 1 \mathrm{~S}$ sample $\left(\mathrm{W}_{\text {PDMS resin }}: W_{\text {Silicone oil }}=1: 1\right)$, and 1P2S sample $\left(\mathrm{W}_{\mathrm{PDMS} \text { resin: }} \mathrm{W}_{\text {Silicone oil }}=1: 2\right)$.

\subsection{Surface Characterization}

The surface morphologies of different samples were examined using a scanning electron microscope (SEM, FEI Quanta 250, Hillsboro, OR, USA) with an accelerating voltage of $20 \mathrm{kV}$. Before the observation, the samples were immersed in $\mathrm{n}$-hexane for $48 \mathrm{~h}$ to remove the dimethyl silicone oil. An optical microscope (Zeiss, AixonX1, Oberkochen, Germany) was used to observe the self-replenishment process of dimethyl silicone oil on different surfaces. The original silicone oil on the surface was removed by commercial oil absorption paper, and then the surface condition was photographed and recorded every $10 \mathrm{~min}$ until the sample surface did not change. The wettability of different surfaces was characterized by a goniometer (Dataphysics, OCA20, Filderstadt, Germany). The sessile drop method was adopted to measure the static water contact angles (WCAs) [42]. By tilting the surface from $0^{\circ}$ to a higher angle until the water droplet rolled off automatically, the tilting angle was recorded as the sliding angle of the surface.

\subsection{Oil Loss/Replenishment Cycle Tests}

In order to characterize the oil replenishment capability and stability of different surfaces, the oil loss/replenishment cycle tests were carried out. In this test, to avoid contaminating the instrument, we put the sample into a small plastic petri dish for testing. The weight of the new sample with petri dish was measured by a Mettler Toledo electronic balance (precision $\pm 0.1 \mathrm{mg}$ ) and recorded as $m_{0}$. When the silicone oil film on the sample surface was stable, we used oil absorption paper to wipe off the oil film. After removing the oil film, the weight of the sample with petri dish was measured again. The above steps was viewed as one cycle. After $n$ times of cycle, the weight of the sample with petri dish was recorded as $m_{n}$. The cumulative weight loss rate $(\omega)$ was calculated by following equation:

$$
\omega=\left(m_{0}-m_{n}\right) / m_{0} \times 100 \%
$$

\subsection{Compression Mechanical Property Tests}

The compression tests were conducted to characterize the influence of silicone oil content on the mechanical property of different samples. According to the national standard GBT 7757-2009, the compression mechanical property of the samples with different silicone oil contents was measured with the electronic universal testing machine (Changchun Kexin Testing Instrument Co. LTD., WDW-100, Changchun, China). The diameter and the thickness of the samples were $\sim 30 \mathrm{~mm}$ and $\sim 10 \mathrm{~mm}$, respectively. During the measurement, the loading speed was controlled at $10 \mathrm{~mm} / \mathrm{min}$. Firstly, the sample was cyclically compressed three times to $50 \%$ of the strain of the sample, and then the 
stress-strain curve was obtained by compressing the sample at the same speed. The elastic modulus value was obtained by calculating the slope of the linear region of the stress-strain curve.

\subsection{Anti-Icing Tests}

The ice adhesion strength on the sample surface was tested using the device and method shown in Figure 1. A plastic shell $(2 \mathrm{~cm} \times 2 \mathrm{~cm} \times 3 \mathrm{~cm})$ was placed on the sample surface, and then $5 \mathrm{~mL}$ of deionized water was added into it. Then, the setup was put into a refrigerator with a temperature of about $-20^{\circ} \mathrm{C}$ for $3 \mathrm{~h}$ until the deionized water froze and adhered to the sample surface. At the beginning of the test, the setup was quickly transferred to the cold stage to maintain the low temperature environment $\left(-20^{\circ} \mathrm{C}\right)$ around the sample surface. Subsequently, the ice adhesion strength of the solid ice column to the surface was measured with a digital display thrust dynamometer (NSCING Co. LTD, SH-III-200) immediately at $-20^{\circ} \mathrm{C}$. The probe moved towards the ice column at a speed of $10 \mathrm{~mm} / \mathrm{min}$ and the probe diameter was $4 \mathrm{~mm}$. When the probe separated the ice column from the sample surface, the deicing process was completed, and the force value was recorded. The ice adhesion strength was calculated by following equation:

$$
\tau=100 F / A
$$

in which $\tau$ is the ice adhesion strength $(\mathrm{Pa}), F$ represents the thrust force $(\mathrm{N})$, and $A$ is the contact area between the solid ice and the sample surface $\left(\mathrm{m}^{2}\right)$. This $\tau$ value was actually the shear strength between the solid ice column and the sample surface, which has been adopted as the main parameter to evaluate the ice adhesion strength in many studies. Five different positions were selected for each sample to measure the adhesion strength values. Similar test method can also be found in other literatures [43]. In order to study the anti-icing durability of different sample surfaces, icing/deicing cycle tests were carried out in this experiment. After each cycle, the ice adhesion strengths of different sample surfaces were calculated. At the same time, the water sliding angles of different sample surfaces were also tested. The icing/deicing cycle tests were carried out continuously without interruption at a constant temperature of $-20{ }^{\circ} \mathrm{C}$.

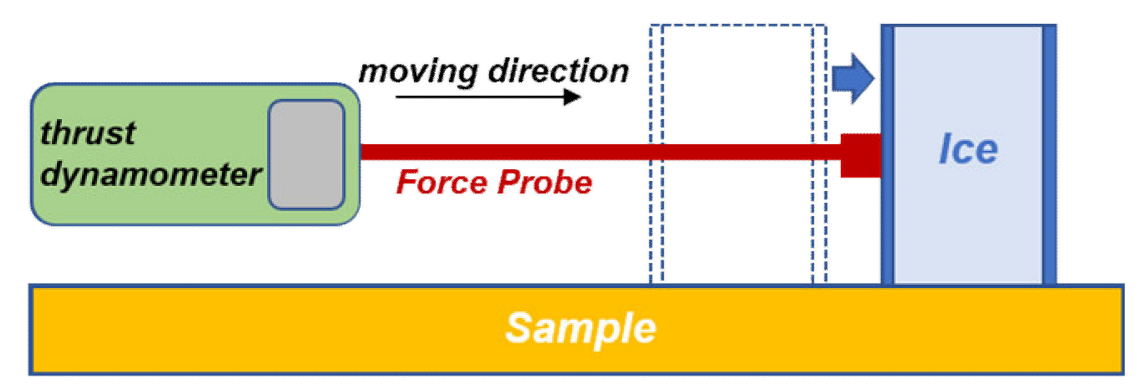

Figure 1. The set-up configuration of the ice adhesion strength measurement.

\section{Results}

\subsection{Preparation Process and Surface Morphology}

The PDMS prepolymer used in the preparation process was vinyl-terminated polydimethylsiloxane, and the curing agent was hydroxyl-terminated polydimethylsiloxane. Under high temperature, the vinyl at the end of the polydimethylsiloxane disconnects and reacts with the hydroxyl group in the molecular structure of the curing agent to accomplish a cross-linking process [44]. In this way, the molecular chains of PDMS resin and curing agent construct a three-dimensional network structure. The component of dimethyl silicone oil is methyl-terminated polydimethylsiloxane. Since the methyl group is inert, dimethyl silicone oil does not participate in the above cross-linking curing reaction. The PDMS resin and dimethyl silicone oil used in the experiment were both linear polydimethylsiloxane, only with different end groups. Hence, the compatibility between PDMS resin and dimethyl silicone oil was good, and they could be evenly mixed after mechanical stirring and without layering. 
Figure 2 shows the surface and cross-section SEM images of the pure sample, 1P1S sample, and $1 \mathrm{P} 2 \mathrm{~S}$ sample after oil removal. Although the amount of silicone oil was changed, the surface and cross-section morphologies of the different samples did not change significantly. In addition to a few dust particles, the surface and cross-section morphologies of the samples were smooth without obvious holes or rough microstructures. Since the silicone oil was dissolved by n-hexane, the images in Figure 2 were mainly the morphologies of the PDMS frameworks. Zhang et al. used a similar one-step method to mix liquid paraffin and silicone, but the poor compatibility between the liquid paraffin and silicone resulted in the distribution of the paraffin in the silicone as larger spherical droplet after curing [45]. When the paraffin was dissolved, obvious holes were left in the silicone framework. Therefore, the morphology results (Figure 2) indicate that the dimethyl silicone oil used in this study had excellent compatibility with the PDMS resin, and the degree of phase separation was very small.

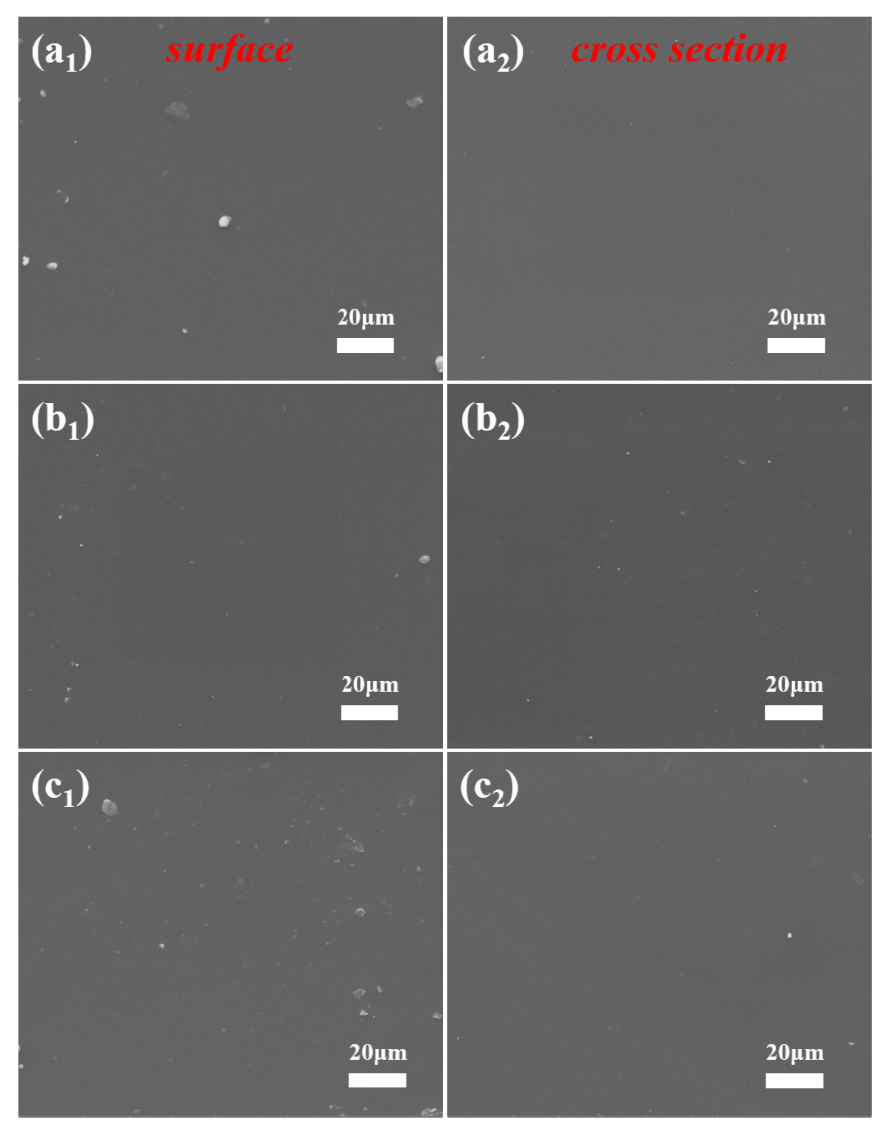

Figure 2. Surface and cross-section SEM images of polydimethylsiloxane (PDMS) frameworks of the $\left(\mathbf{a}_{1}, \mathbf{a}_{2}\right)$ pure sample, $\left(\mathbf{b}_{1}, \mathbf{b}_{2}\right)$ 1P1S sample, and $\left(\mathbf{c}_{1}, \mathbf{c}_{2}\right)$ 1P2S sample.

\subsection{Self-Complementing Behavior}

Figure 3 shows the surface optical morphologies of different samples before and after removal of the surface silicone oil. For the pure sample, the surface morphology of the sample did not change significantly in the whole experiment process because there was no silicone oil involved (Figure 3a). The black spots on the sample surface were supposed to be dust particles. For the 1P1S sample, the whole surface of the 1P1S sample was covered by the silicone oil film before oil removal (Figure $3 b_{1}$ ). After the surface oil film was wiped off, the surface of the 1P1S sample was completely covered by the silicone oil film again after $6 \mathrm{~h}$ (Figure $3 \mathrm{~b}_{4}$ ). In contrast, when the content of silicone oil in the sample was further enhanced, the surface of the $1 \mathrm{P} 2 \mathrm{~S}$ sample was completely covered by silicone oil film again within only $4 \mathrm{~h}$ (Figure $3 \mathrm{c}_{3}$ ). After $4 \mathrm{~h}$, the silicone oil film on the surface of the 1P2S sample was relatively stable. This result suggests that the LIS had an excellent self-replenishment function to 
the oil film on the sample surface. Furthermore, with the increase of the amount of silicone oil in the sample matrix, the replenishment speed of silicone oil also became faster.

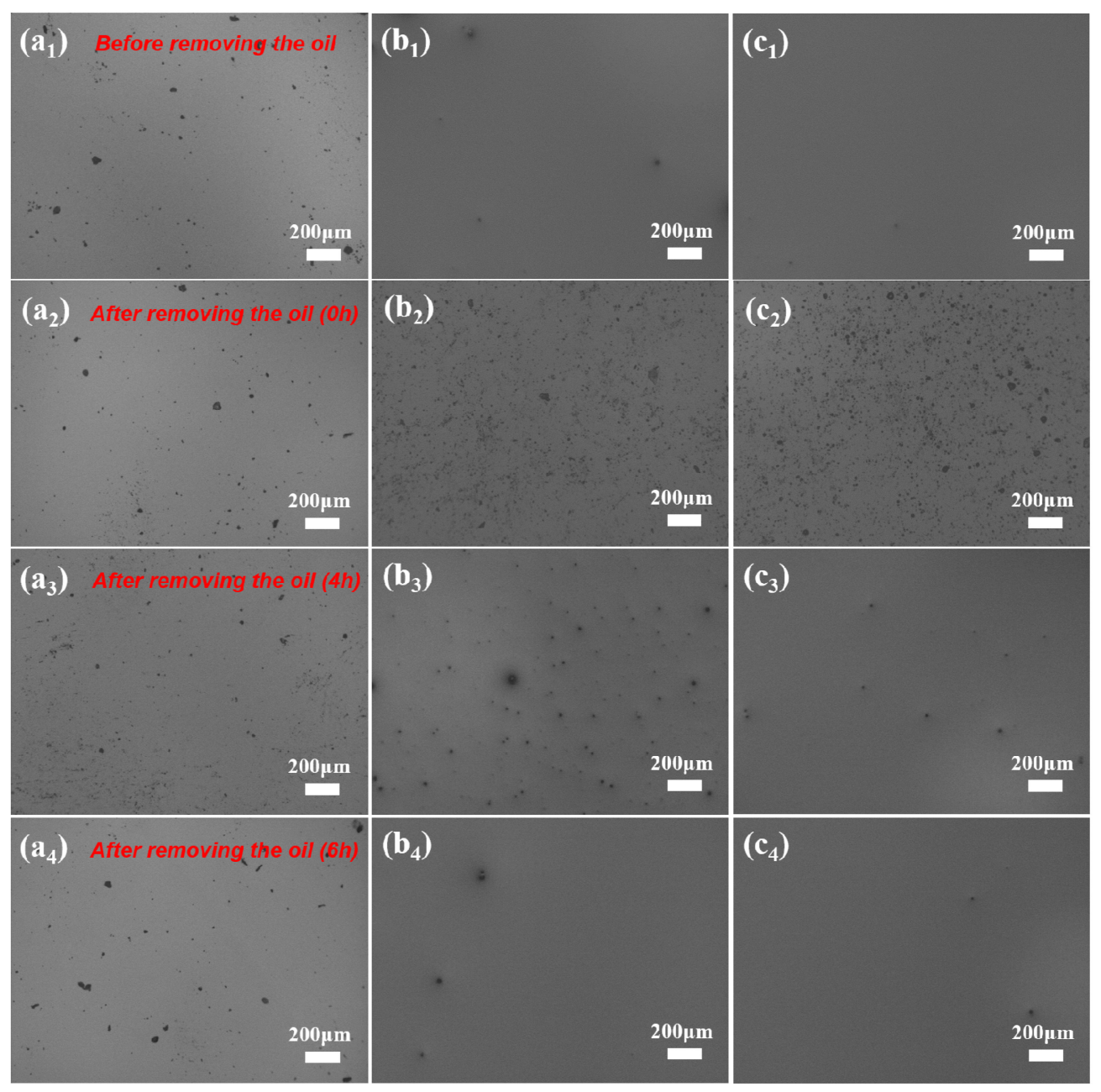

Figure 3. The oil replenishment processes of different sample surfaces: $\left(\mathbf{a}_{1}-\mathbf{a}_{4}\right)$ pure sample, $\left(\mathbf{b}_{1}-\mathbf{b}_{4}\right)$ 1P1S sample, and $\left(\mathbf{c}_{1}-\mathbf{c}_{4}\right)$ 1P2S sample.

Figure 4 shows the evolution process of the cumulative weight loss rate of different samples in the oil replenishment/loss cycle tests. It can be observed that the curves of the 1P1S sample and 1P2S sample contained two phases. In the first stage, as the test number increased, the cumulative weight loss rate gradually increased, which was mainly related to the continuous replenishment of silicone oil to the sample surface from the silicone framework. Once the test number was too much, the cumulative weight loss rate basically did not change with the increase of the test number. It was mainly caused by the complete depletion of silicone oil in the sample matrix. With the increase of the amount of silicone oil in the sample, it was obvious that the cumulative weight loss rate increased faster in the first stage. This indicated that $1 \mathrm{P} 2 \mathrm{~S}$ sample supplemented more silicone oil each time. In addition, due to the increased amount of silicone oil in the 1P2S sample, the effective time of replenishment behavior (the first stage) was also longer than in the 1P1S sample. The weight loss results demonstrated that the 1P2S sample had a larger replenishment amount in each cycle and it had a more durable lubrication effect (until 24 days). 


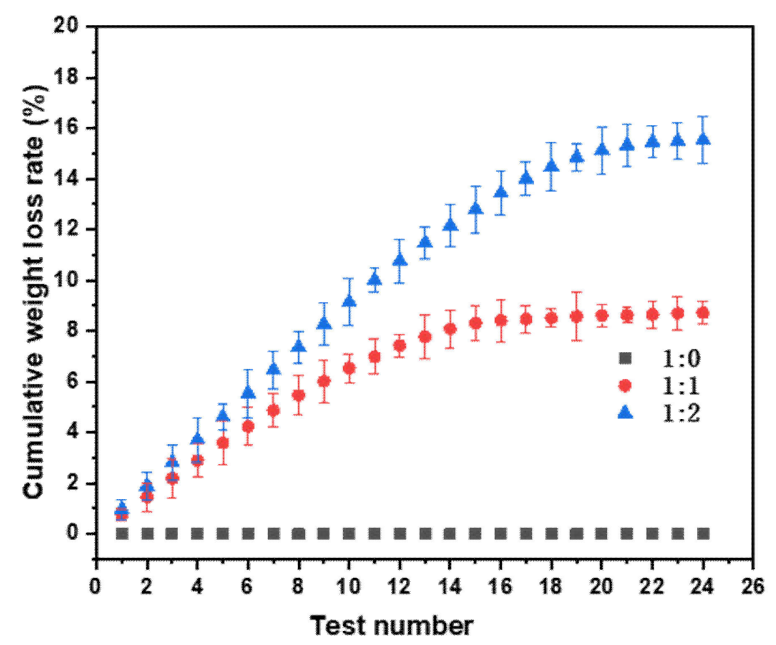

Figure 4. The cumulative weight loss rate values of different samples after different test numbers in the oil replenishment/loss cycle tests.

The self-replenishment ability of the LIS was derived from the good compatibility between silicone oil and PDMS resin. In this experiment, after the PDMS resin and silicone oil were mixed directly, the phenomenon of no stratification was also verified this point. After the curing process, the silicone oil molecules were filled into the three-dimensional network of the PDMS framework. The low rotational energy barrier $(3.3 \mathrm{~kJ} / \mathrm{mol})$ of the silicone oil molecule around the $\mathrm{Me}_{2} \mathrm{Si}-\mathrm{O}$ bond made the silicone oil easily diffuse within the polymer network [46]. Thus, once the surface silicone oil film was removed, the inner silicone oil quickly diffused to the sample surface and completed the supplement process.

\subsection{Surface Wettability}

Figure 5 shows the results of WCA measurements of different sample surfaces before and after removing the oil film. For the pure sample, the WCA values were stable around $110^{\circ}$, which demonstrated the hydrophobicity of the silicone matrix. With the increase of the amount of silicone oil in the samples, the WCA values decreased slowly. This may have resulted from the fact that the surface energy of silicone oil $\left(\sim 21 \mathrm{~mJ} \cdot \mathrm{m}^{-2}\right)$ was slightly higher than that of the PDMS resin $\left(\sim 20 \mathrm{~mJ} \cdot \mathrm{m}^{-2}\right)[47,48]$. In addition, when the oil films on the surfaces of the 1P1S sample and the 1P2S sample were just removed, the WCA values increased slightly, which also indicated that the surface energy of silicone oil was slightly higher. After $6 \mathrm{~h}$, the WCA values on the surfaces of the 1P1S and $1 \mathrm{P} 2 \mathrm{~S}$ samples were restored to the original values before removing the oil, which again confirmed the rapid self-replenishment ability of the $1 \mathrm{P} 1 \mathrm{~S}$ and $1 \mathrm{P} 2 \mathrm{~S}$ samples to the surface oil films. On the whole, although the WCA values of different sample surfaces varied slightly, the overall variation amplitude was very small.

The sliding angles of different sample surfaces before and after removing the oil film were further tested, and the results are shown in Figures 6-8. Generally speaking, the surface sliding angle was smaller due to the existence of liquid oil film on the surface, making the surface liquid water slide more easily, which can also be seen as the self-cleaning function of LISs. As shown in Figure 6, although the pure sample surface was tilted to $90^{\circ}$, the water droplet still could not slide down but was firmly anchored on the pure sample surface. This phenomenon suggests that the pure sample surface did not have lubrication ability. Once the silicone oil was introduced into the PDMS matrix, the oil film on the sample surface rapidly reduced the water slide angle to about $4^{\circ}$ (Figure 7 ). The surface of the 1P1S sample exhibited excellent lubrication to liquid water, indicating that the presence of silicone oil film was the key factor for the lubrication effect. When the oil film was removed, the water droplet did not slide until the surface was tilted to about $78^{\circ}$. Under the influence of silicone oil inside the sample, the sliding angle of the 1P1S sample after removing the oil film was still smaller than that of the pure sample. After the oil film was supplemented, the water sliding angle was restored, which 
again revealed that the lubrication ability of the 1P1S sample mainly came from the oil film. When the amount of silicone oil in the sample continued to increase, the sliding angle of 1P2S sample further decreased to about $2^{\circ}$ (Figure 8 ). Similarly, when the oil film was replenished within $6 \mathrm{~h}$, the sliding angle value was recovered. This was due to the increase of the supplement amount of silicone oil on the surface, which improved the continuity and fluidity of the oil film, and undoubtedly contributed to the reduction of the sliding angle. The results of sliding angle measurements not only showed that the 1P1S and 1P2S samples had self-replenishing ability, but also indicated that the excellent lubrication properties of the 1P1S and 1P2S samples could effectively reduce the adhesion of liquid water and other pollutants on the sample surfaces.

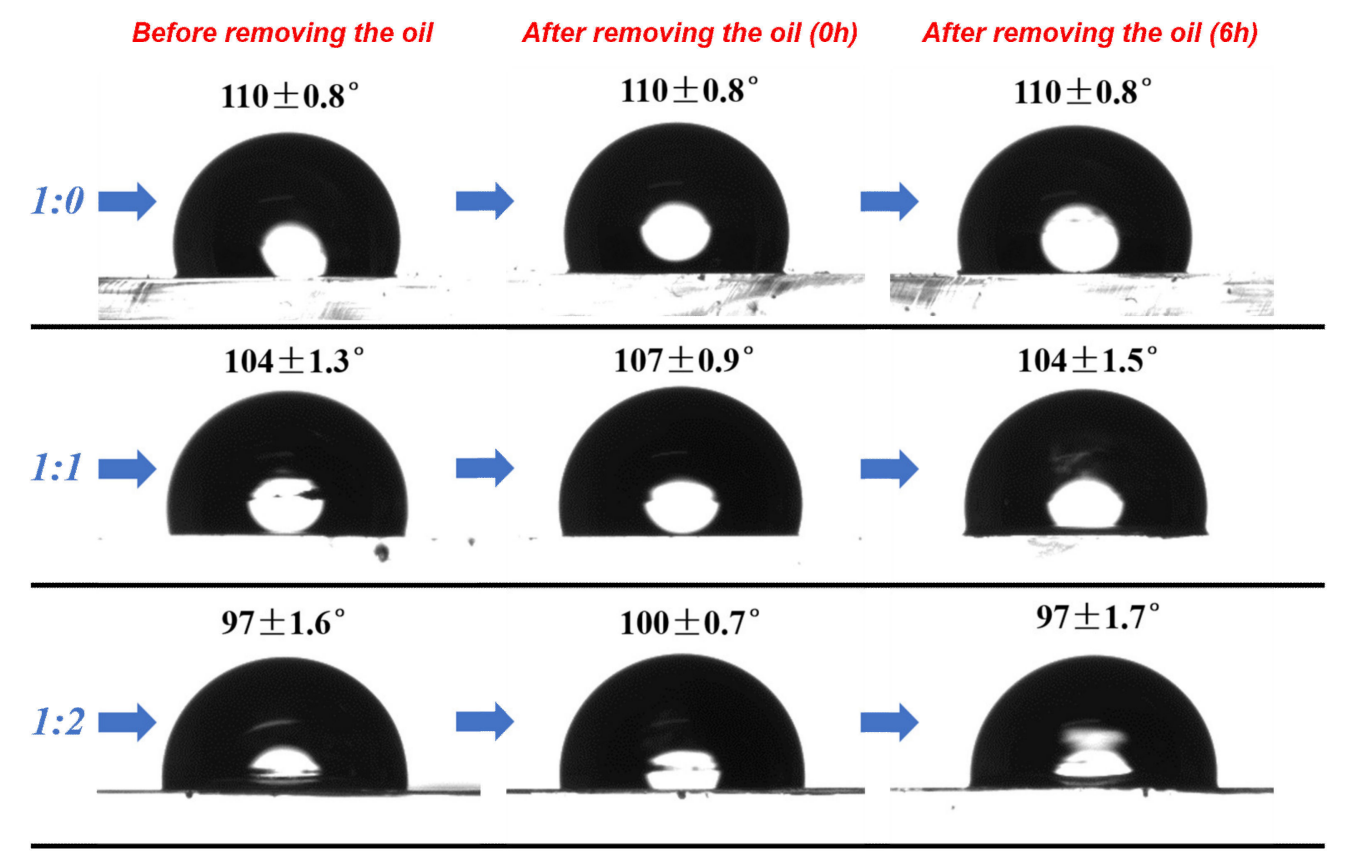

Figure 5. Water contact angles before and after removing the oil from different sample surfaces.

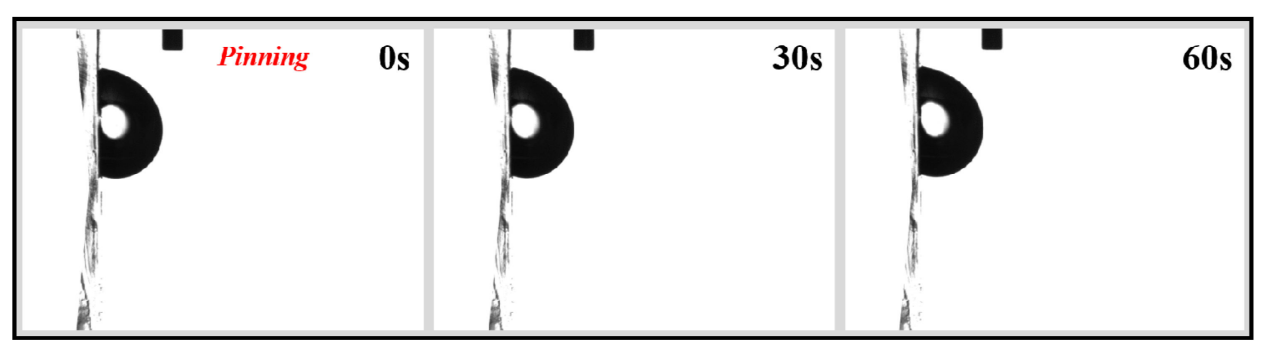

Figure 6. The pinning state of the water droplet on the pure sample surface. 


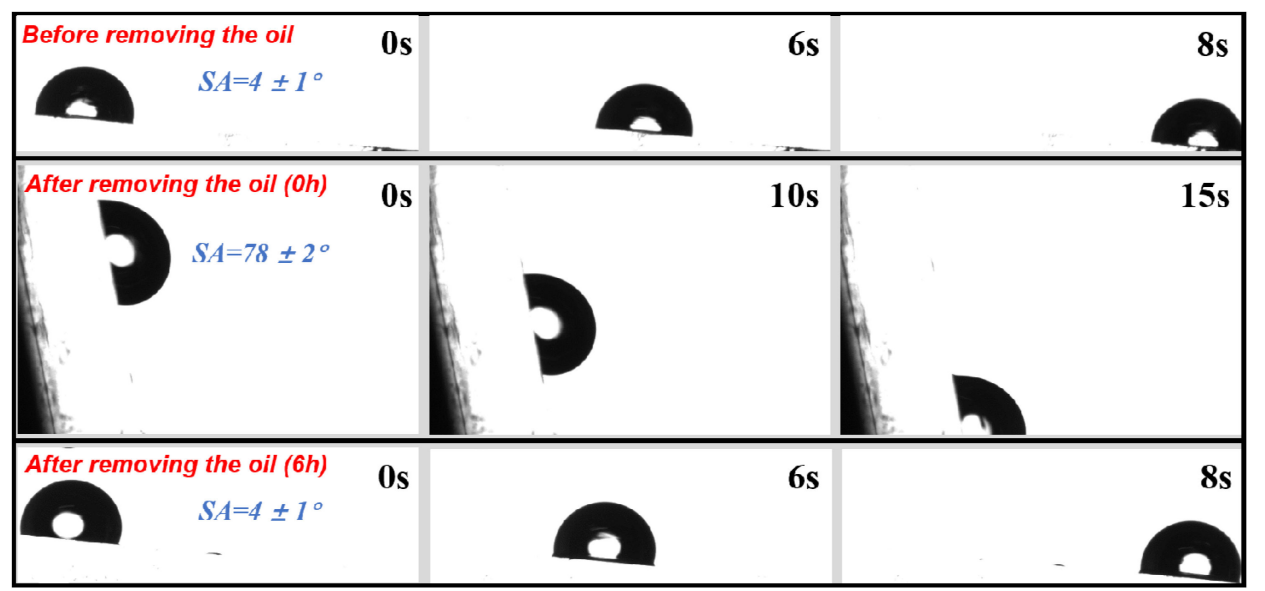

Figure 7. Sliding angles of the 1P1S sample before and after removing the oil from the surface.

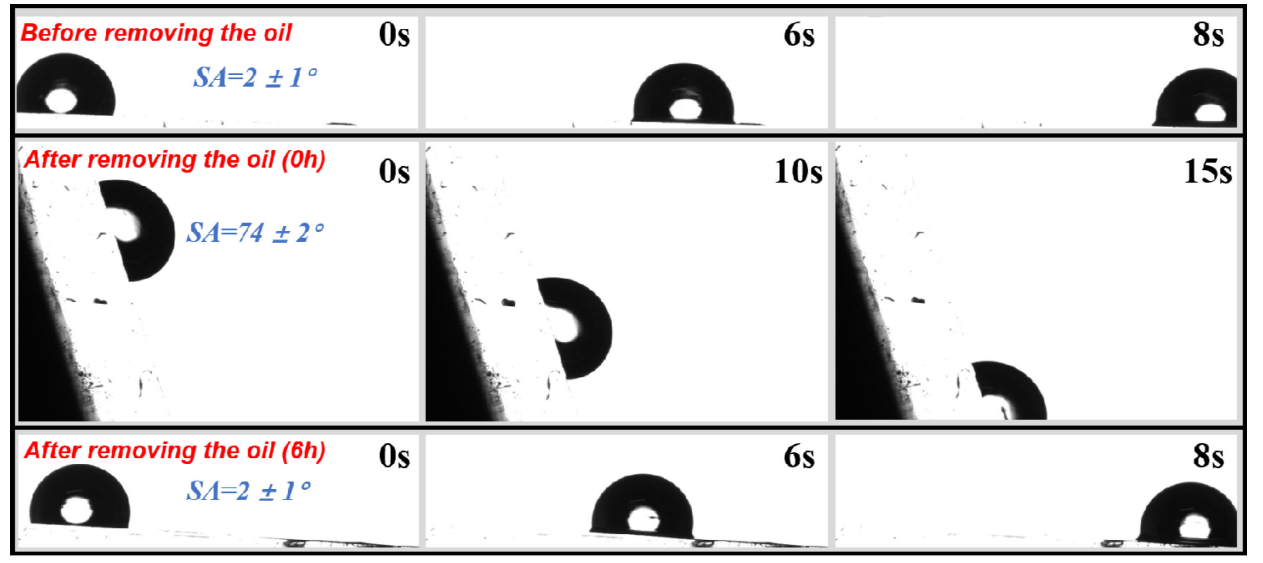

Figure 8. Sliding angles of the $1 \mathrm{P} 2 \mathrm{~S}$ sample before and after removing the oil from the surface.

\subsection{Mechanical Properties}

In order to study the effect of silicone oil content on the mechanical properties of the PDMS matrix, we examined the compression stress-strain curves of the samples with different silicone oil contents, and the results are shown in Figure 9a. When the amount of silicone oil in the sample was tuned, the stress-strain curve also changed obviously. Under the same stress condition, the strain was enhanced with the increase of silicone oil content. This indicates that the addition of silicone oil reduced the compression strength of the PDMS resin and then promoted the deformation of the silicone resin matrix. According to the stress-strain curves in Figure 9a, the change of the elastic modulus value with the increase of silicone oil content was obtained, as shown in Figure 9b. The compression elastic modulus of the pure sample was $4.609 \mathrm{MPa}$, while that of the 1P1S and 1P2S samples were only $0.879 \mathrm{MPa}$ and $0.404 \mathrm{MPa}$, respectively, indicating that the addition of silicone oil greatly reduced the compression elastic modulus of PDMS resin. For polymer materials, their mechanical properties are related to the density of their internal crosslinking networks. In this study, the silicone oil existed in the crosslinking network gap of the PDMS resin in liquid form. In order to accommodate more silicone oil, the PDMS resin had to reduce its crosslinking density to enlarge the interior space, which led to the decrease of its strength. In spite of this, it was found that no significant damage occurred when the compression strains of the three specimens were $50 \%$. This indicates that although the compression strength decreased, the 1P1S and 1P2S samples still had good mechanical properties, which did not affect their practical applications. 

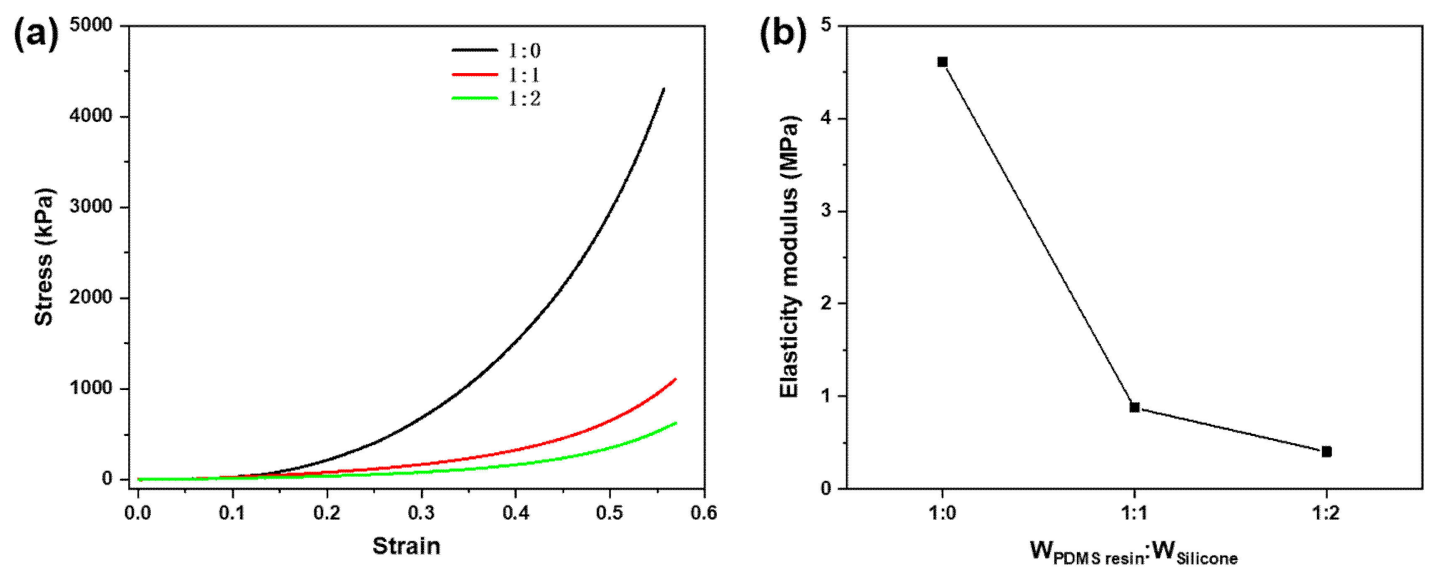

Figure 9. (a) Compressive stress-strain curves and (b) compressive elastic modulus values of different samples.

\subsection{Anti-Icing Properties}

As mentioned above, the slippery LIS prepared in this study had the ability to self-supplement and repair the oil film on the sample surface, which was beneficial to the improvement of anti-icing durability of the LIS. We tracked and monitored the change of ice adhesion strength on three sample surfaces with the increase of test number of icing/deicing cycles, and the results are shown in Figure 10a. Prior to the icing/deicing cycle tests, the pure sample showed extremely high ice adhesion strength (about $75 \mathrm{kPa}$ ), and solid ice was difficult to separate from the pure sample surface. Under the influence of the silicone oil film, the ice adhesion strengths on the surfaces of the 1P1S and 1P2S samples were greatly reduced, which were only $\sim 25 \mathrm{kPa}$ and $\sim 15 \mathrm{kPa}$, respectively. The silicone oil film isolated the solid ice from the sample surface, and the binding force between the solid ice and the silicone oil was significantly lower. In addition, silicone oil contained in the PDMS resin framework reduced the elastic modulus and cross-linking density of the PDMS matrix, which made the interface slip between the solid ice and sample surface more easily and reduced the ice adhesion strength [49]. The 1P2S sample exhibited the lowest ice adhesion strength, which was related to the more complete oil film on the surface of the $1 \mathrm{P} 2 \mathrm{~S}$ sample.
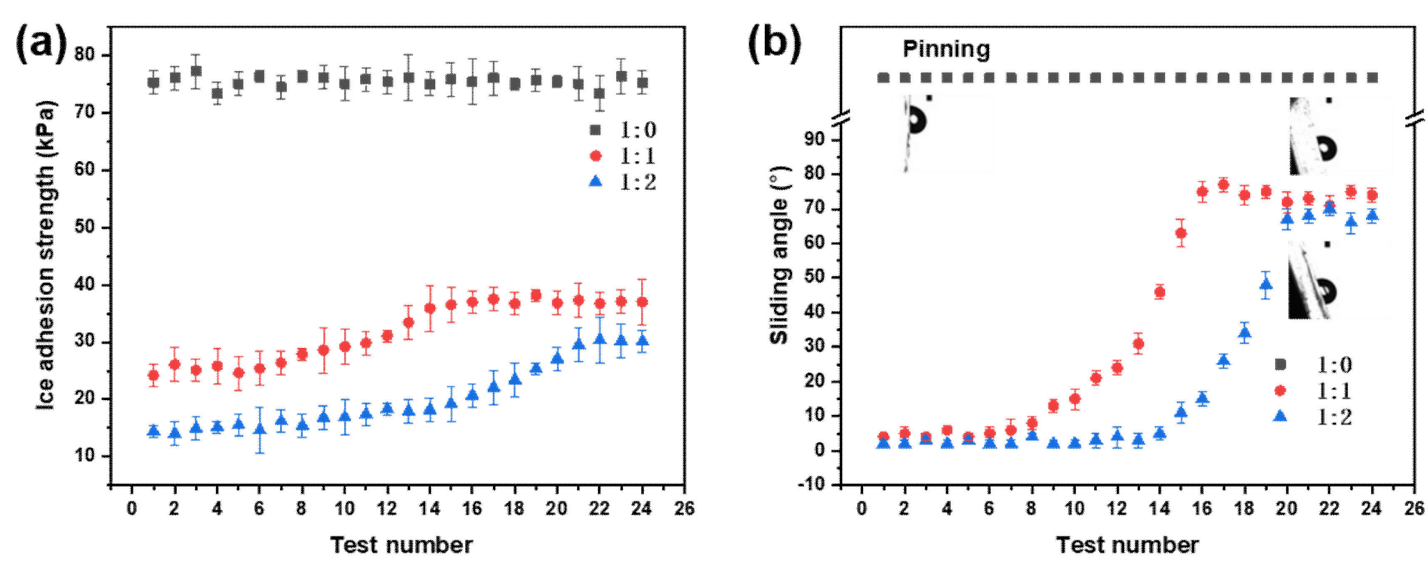

Figure 10. The variation of (a) ice adhesion strength and (b) sliding angle of different sample surfaces during the icing/deicing cycle tests.

In Figure 10a, the ice adhesion strength on the surface of pure sample hardly changed during the 24 cycles of icing/deicing tests. After 10 cycles of icing/deicing tests, the ice adhesion strength on the surface of the 1P1S sample began to increase slowly. According to the test results of the water sliding angle, after 10 cycles the water sliding angle on the surface of the 1P1S sample began to increase 
gradually. This indicated that with the gradual consumption of silicone oil, the ability of the 1P1S sample to supplement the oil film on the surface started to weaken after 10 cycles. This was also the reason that the ice adhesion strength and water sliding angle increased after 10 cycles. Nevertheless, after 24 cycles of icing/deicing tests, the ice adhesion strength on the surface of the 1P1S sample was still very low and was much lower than that on the surface of the pure sample. In contrast, the surface of the 1P2S sample exhibited the lowest ice adhesion strength over 24 cycles of icing/deicing tests. Moreover, it was not until the $14^{\text {th }}$ cycle that the water sliding angle and ice adhesion strength on the surface of the 1P2S sample began to increase slowly, which was mainly caused by the larger amount of silicone oil in the 1P2S sample matrix and the stronger self-replenishment ability of the 1P2S sample (Figure 3). Even so, the ice adhesion strength of the 1P2S sample was still much lower than that of similar LISs reported in other literatures [50]. The above test results show that the 1P2S sample exhibited the best anti-icing ability with the help of lubrication of the silicone oil film and its excellent self-supplementation ability, which has great potential for anti-icing applications in the future.

\section{Conclusions}

This work introduced one kind of self-replenishing LIS prepared by a simple one-step method. The influence of the amount of silicone oil on the lubrication ability and self-replenishment ability of the sample was characterized by morphology, wettability, and weight loss analysis. The anti-icing performances of pure PDMS and LIS were investigated by icing/deicing cycle tests. The following conclusions can be obtained:

(1) The dimethyl silicone oil (PMX-200) showed good compatibility with PDMS resin. The addition of silicone oil in the PDMS matrix greatly reduced the surface water slide angle and improved the surface lubrication ability.

(2) The presence of silicone oil endowed the LIS with a self-replenishment ability to the surface oil film. With the increase of silicone oil content in the PDMS matrix, the self-replenishment rate and amount were enhanced significantly, which was beneficial to the recovery of surface lubrication.

(3) The LIS exhibited low ice adhesion strength because of the presence of the oil film. Moreover, the ice adhesion strength on the LIS was still very low after 24 cycles of the icing/deicing tests. The LIS showed excellent and durable anti-icing performance.

Author Contributions: J.Z. and B.L. designed the experiments and wrote the manuscript. Y.T., F.W., Q.C., and F.Z. assisted in performing some tests. H.Q. and L.M. helped to revise the manuscript. All authors have read and agreed to the published version of the manuscript.

Funding: This work is supported by the China Postdoctoral Science Foundation (2019M660453), the Basic Research and Strategic Reserve Technology Research Fund (project of China National Petroleum Corporation (2018Z-01)), and the National Material Environmental Corrosion Science Data Center.

Acknowledgments: We thank Jingzhi Yang and Tong Liu for technical assistance.

Conflicts of Interest: The authors declare no conflict of interest.

\section{References}

1. Kreder, M.J.; Alvarenga, J.; Kim, P.; Aizenberg, J. Design of anti-icing surfaces: Smooth, textured or slippery? Nat. Rev. Mater. 2016, 1, 15003. [CrossRef]

2. Lv, J.Y.; Song, Y.L.; Jiang, L.; Wang, J.J. Bio-inspired strategies for anti-icing. ACS Nano 2014, 8, 3152-3169. [CrossRef] [PubMed]

3. Dou, R.M.; Chen, J.; Zhang, Y.F.; Wang, X.P.; Cui, D.P.; Song, Y.L.; Jiang, L.; Wang, J. Anti-icing coating with an aqueous lubricating layer. ACS Appl. Mater. Inter. 2014, 6, 6998-7003. [CrossRef] [PubMed]

4. Wen, S.F.; Wang, Y.M.; Zhang, Z.M.; Liu, Y.L. Application of anti-icing coating based on adsorption of functional substances by microporous sphere. Prog. Org. Coat. 2019, 137, 105320. [CrossRef]

5. Zuo, Z.P.; Liao, R.J.; Guo, C.; Yuan, Y.; Zhao, X.T.; Zhuang, A.Y.; Zhang, Y.Y. Fabrication and anti-icing property of coral-like superhydrophobic aluminum surface. Appl. Surf. Sci. 2015, 331, 132-139. [CrossRef] 
6. Zhang, S.N.; Huang, J.Y.; Cheng, Y.; Yang, H.; Chen, Z.; Lai, Y.K. Bioinspired surfaces with superwettability for anti-Icing and ice-phobic application: Concept, mechanism, and design. Small 2017, 13, 1701867. [CrossRef]

7. Pan, S.; Wang, N.; Xiong, D.S.; Deng, Y.L.; Shi, Y. Fabrication of superhydrophobic coating via spraying method and its applications in anti-icing and anti-corrosion. Appl. Surf. Sci. 2016, 389, 547-553. [CrossRef]

8. Cheng, T.T.; He, R.; Zhang, Q.H.; Zhan, X.L.; Chen, F.Q. Magnetic particle-based super-hydrophobic coatings with excellent anti-icing and thermoresponsive deicing performance. J. Mater. Chem. A 2015, 3, 21637-21646. [CrossRef]

9. Zhang, F.; Qian, H.C.; Wang, L.T.; Wang, Z.; Du, C.W.; Li, X.G.; Zhang, D.W. Superhydrophobic carbon nanotubes/epoxy nanocomposite coating by facile one-step spraying. Surf. Coat. Technol. 2018, 341, 15-23. [CrossRef]

10. Tian, X.L.; Verho, T.; Ras, R.H.A. Moving superhydrophobic surfaces toward real-world applications. Science 2016, 352, 142-143. [CrossRef]

11. Qian, H.C.; Li, M.L.; Li, Z.; Lou, Y.T.; Huang, L.Y.; Zhang, D.W.; Xu, D.K.; Du, C.W.; Lu, L.; Gao, J. Mussel-inspired superhydrophobic surfaces with enhanced corrosion resistance and dual-action antibacterial properties. Mater. Sci. Eng. C 2017, 80, 566-577. [CrossRef] [PubMed]

12. Jeevahan, J.; Chandrasekaran, M.; Joseph, G.B.; Durairaj, R.B.; Mageshwaran, G. Superhydrophobic surfaces: A review on fundamentals, applications, and challenges. J. Coat. Technol. Res. 2018, 15, 231-250. [CrossRef]

13. Qian, H.C.; Zhang, D.W.; Deng, L.P.; Huang, L.Y.; Xu, D.K.; Du, C.W.; Li, X.G. The role of surface morphology in the barrier properties of epoxy coatings in different corrosion environments. Prog. Org. Coat. 2017, 104, 199-209. [CrossRef]

14. Goetz, L.A.; Jalvo, B.; Rosal, R.; Mathew, A.P. Superhydrophilic anti-fouling electrospun cellulose acetate membranes coated with chitin nanocrystals for water filtration. J. Membr. Sci. 2016, 510, 238-248. [CrossRef]

15. Lee, C.; Choi, C.H.; Kim, C.J. Superhydrophobic drag reduction in laminar flows: A critical review. Exp. Fluids 2016, 57, 176. [CrossRef]

16. Huang, J.Y.; Li, S.H.; Ge, M.Z.; Wang, L.N.; Xing, T.L.; Chen, G.Q.; Liu, X.F.; Al-Deyab, S.S.; Zhang, K.Q.; Chen, T.; et al. Robust superhydrophobic $\mathrm{TiO}_{2} @$ fabrics for UV shielding, self-cleaning and oil-water separation. J. Mater. Chem. A 2015, 3, 2825-2832. [CrossRef]

17. Qian, H.C.; Xu, D.K.; Du, C.W.; Zhang, D.W.; Li, X.G.; Huang, L.Y.; Deng, L.P.; Tu, Y.C.; Mol, J.M.C.; Terryn, H.A. Dual-action smart coatings with a self-healing superhydrophobic surface and anti-corrosion properties. J. Mater. Chem. A 2017, 5, 2355-2364. [CrossRef]

18. Wang, N.; Xiong, D.; Deng, Y.; Shi, Y.; Wang, K. Mechanically robust superhydrophobic steel surface with anti-icing, UV-durability, and corrosion resistance properties. ACS Appl. Mater. Inter. 2015, 7, 6260-6272. [CrossRef]

19. Boinovich, L.B.; Emelyanenko, A.M.; Emelyanenko, K.A.; Maslakov, K.I. Anti-icing properties of a superhydrophobic surface in a salt environment: An unexpected increase in freezing delay times for weak brine droplets. Phys. Chem. Chem. Phys. 2016, 18, 3131-3136. [CrossRef]

20. Zhang, D.W.; Qian, H.C.; Wang, L.T.; Li, X.G. Comparison of barrier properties for a superhydrophobic epoxy coating under different simulated corrosion environments. Corros. Sci. 2016, 103, 230-241. [CrossRef]

21. Simpson, J.T.; Hunter, S.R.; Aytug, T. Superhydrophobic materials and coatings: A review. Rep. Prog. Phys. 2015, 78, 086501. [CrossRef] [PubMed]

22. Zhi, J.H.; Zhang, L.Z.; Yan, Y.; Zhu, J. Mechanical durability of superhydrophobic surfaces: The role of surface modification technologies. Appl. Surf. Sci. 2017, 392, 286-296. [CrossRef]

23. Liu, B.; Zhang, K.; Tao, C.; Zhao, Y.; Li, X.; Zhu, K.; Yuan, X. Strategies for anti-icing: Low surface energy or liquid-infused? RSC Adv. 2016, 6, 70251-70260. [CrossRef]

24. Latthe, S.S.; Sutar, R.S.; Bhosale, A.K.; Nagappan, S.; Ha, C.S.; Sadasivuni, K.K.; Liu, S.H.; Xing, R. Recent developments in air-trapped superhydrophobic and liquid-infused slippery surfaces for anti-icing application. Prog. Org. Coat. 2019, 137, 105373. [CrossRef]

25. Liu, X.; Chen, H.; Zhao, Z.; Yan, Y.; Zhang, D. Slippery liquid-infused porous electric heating coating for anti-icing and de-icing applications. Surf. Coat. Technol. 2019, 374, 889-896. [CrossRef]

26. Wang, P.; Zhang, D.; Lu, Z. Slippery liquid-infused porous surface bio-inspired by pitcher plant for marine anti-biofouling application. Colloid. Surf. B 2015, 136, 240-247. [CrossRef]

27. Tuo, Y.; Zhang, H.; Chen, W.; Liu, X. Corrosion protection application of slippery liquid-infused porous surface based on aluminum foil. Appl. Surf. Sci. 2017, 423, 365-374. [CrossRef] 
28. Semprebon, C.; McHale, G.; Kusumaatmaja, H. Apparent contact angle and contact angle hysteresis on liquid infused surfaces. Soft Matter 2017, 13, 101-110. [CrossRef]

29. Qiu, Z.; Qiu, R.; Xiao, Y.; Zheng, J.; Lin, C. Slippery liquid-infused porous surface fabricated on CuZn: A barrier to abiotic seawater corrosion and microbiologically induced corrosion. Appl. Surf. Sci. 2018, 457, 468-476. [CrossRef]

30. Xiang, T.F.; Zhang, M.; Sadig, H.R.; Li, Z.C.; Zhang, M.X.; Dong, C.D.; Yang, L.; Chan, W.M.; Li, C. Slippery liquid-infused porous surface for corrosion protection with self-healing property. Chem. Eng. J. 2018, 345, 147-155. [CrossRef]

31. Manna, U.; Raman, N.; Welsh, M.A.; Zayas-Gonzalez, Y.M.; Blackwell, H.E.; Palecek, S.P.; Lynn, D.M. Slippery liquid-infused porous surfaces that prevent microbial surface fouling and kill non-adherent pathogens in surrounding media: A controlled release approach. Adv. Funct. Mater. 2016, 26, 3599-3611. [CrossRef] [PubMed]

32. Li, J.; Kleintschek, T.; Rieder, A.; Cheng, Y.; Baumbach, T.; Obst, U.; Schwartz, T.; Levkin, P.A. Hydrophobic liquid-infused porous polymer surfaces for antibacterial applications. ACS Appl. Mater. Inter. 2013, 5, 6704-6711. [CrossRef] [PubMed]

33. Wu, D.Q.; Zhang, D.W.; Ye, Y.W.; Ma, L.W.; Minhas, B.; Liu, B.; Terryn, H.A.; Mol, J.M.C.; Li, X.G. Durable lubricant-infused anodic aluminum oxide surfaces with high-aspect-ratio nanochannels. Chem. Eng. J. 2019, 368, 138-147. [CrossRef]

34. Zhang, J.; Gu, C.; Tu, J. Robust slippery coating with superior corrosion resistance and anti-icing performance for AZ31B Mg alloy protection. ACS Appl. Mater. Inter. 2017, 9, 11247-11257. [CrossRef] [PubMed]

35. Heale, F.L.; Parkin, I.P.; Carmalt, C.J. Slippery liquid infused porous $\mathrm{TiO}_{2} / \mathrm{SnO}_{2}$ nanocomposite thin films via aerosol assisted chemical vapour deposition with anti-icing and fog retardant properties. ACS Appl. Mater. Inter. 2019, 11, 41804-41812. [CrossRef]

36. Zhang, M.L.; Chen, R.R.; Liu, Q.; Liu, J.Y.; Yu, J.; Song, D.L.; Liu, P.L.; Gao, L.T.; Wang, J. Long-term stability of a liquid-infused coating with anti-corrosion and anti-icing potentials on $\mathrm{Al}$ alloy. ChemElectroChem 2019, 6, 3911-3919. [CrossRef]

37. Wei, C.Q.; Zhang, G.F.; Zhang, Q.H.; Zhan, X.L.; Chen, F.Q. Silicone oil-infused slippery surfaces based on Sol-Gel process-induced nanocomposite coatings: A facile approach to highly stable bioinspired surface for biofouling resistance. ACS Appl. Mater. Inter. 2016, 8, 34810-34819. [CrossRef]

38. Zhang, P.F.; Chen, H.W.; Zhang, L.W.; Zhang, D.Y. Anti-adhesion effects of liquid-infused textured surfaces on high-temperature stainless steel for soft tissue. Appl. Surf. Sci. 2016, 385, 249-256. [CrossRef]

39. Erbil, H.Y. Improvement of lubricant-infused surfaces for anti-icing applications. Surf. Innov. 2016, 4, 214-217. [CrossRef]

40. Lu, D.X.; Zhang, Y.L.; Han, D.D.; Wang, H.; Xia, H.; Chen, Q.D.; Ding, H.; Sun, H.B. Solvent-tunable PDMS microlens fabricated by femtosecond laser direct writing. J. Mater. Chem. C 2015, 3, 1751-1756. [CrossRef]

41. Zang, S.S.; Zhang, R.; Chen, H.; Lu, Y.D.; Zhou, J.H.; Chang, X.; Qiu, G.X.; Wu, Z.H.; Yang, G. Investigation on artificial blood vessels prepared from bacterial cellulose. Mat. Sci. Eng. C 2015, 46, 111-117. [CrossRef] [PubMed]

42. Qian, H.C.; Yang, J.Z.; Lou, Y.T.; ur Rahman, O.; Li, Z.Y.; Ding, X.; Gao, J.; Du, C.W.; Zhang, D.W. Mussel-inspired superhydrophilic surface with enhanced antimicrobial properties under immersed and atmospheric conditions. Appl. Surf. Sci. 2019, 465, 267-278. [CrossRef]

43. Jin, M.M.; Shen, Y.Z.; Luo, X.Y.; Tao, J.; Xie, Y.H.; Chen, H.F.; Wu, Y. A combination structure of microblock and nanohair fabricated by chemical etching for excellent water repellency and icephobicity. Appl. Surf. Sci. 2018, 455, 883-890. [CrossRef]

44. Wang, C.Y.; Nair, S.S.; Veeravalli, S.; Moseh, P.; Wynne, K.J. Sticky or slippery wetting: Network formation conditions can provide a one-way street for water flow on platinum-cured silicone. ACS Appl. Mater. Inter. 2016, 8, 14252-14262. [CrossRef]

45. Zhuo, Y.Z.; Wang, F.; Xiao, S.B.; He, J.Y.; Zhang, Z.L. One-step fabrication of bioinspired lubricant-regenerable icephobic slippery liquid-infused porous surfaces. ACS Omega 2018, 3, 10139-10144. [CrossRef]

46. Zhu, X.T.; Lu, J.W.; Li, X.M.; Wang, B.; Song, Y.M.; Miao, X.; Wang, Z.J.; Ren, G.N. A simple way to a slippery lubricant impregnated coating with ultra-stability and self-replenishment property. Ind. Eng. Chem. Res. 2019, 58, 8148-8153. [CrossRef] 
47. Crisp, A.; de Juan, E.; Tiedeman, J. Effect of silicone oil viscosity on emulsification. Arch. Ophthalmol. 1987, 105, 546-550. [CrossRef]

48. Martin, S.; Bhushan, B. Transparent, wear-resistant, superhydrophobic and superoleophobic poly (dimethylsiloxane) (PDMS) surfaces. J. Colloid. Interf. Sci. 2017, 488, 118-126. [CrossRef]

49. Golovin, K.; Kobaku, S.P.; Lee, D.H.; DiLoreto, E.T.; Mabry, J.M.; Tuteja, A. Designing durable icephobic surfaces. Sci. Adv. 2016, 2, e1501496. [CrossRef]

50. Liu, Q.; Yang, Y.; Huang, M.; Zhou, Y.X.; Liu, Y.Y.; Liang, X.D. Durability of a lubricant-infused Electrospray Silicon Rubber surface as an anti-icing coating. Appl. Surf. Sci. 2015, 346, 68-76. [CrossRef]

(C) 2020 by the authors. Licensee MDPI, Basel, Switzerland. This article is an open access article distributed under the terms and conditions of the Creative Commons Attribution (CC BY) license (http://creativecommons.org/licenses/by/4.0/). 